\title{
FRICTION AND WEAR REDUCTION BY GRAPHENE NANO PLATELETS FOR HYBRID NANO ALUMINIUM MATRIX COMPOSITE UNDER DRY SLIDING CONDITIONS
}

\author{
Pranav Dev Srivyas *, M. S. Charoo \\ Mechanical Department, National Institute of Technology, Srinagar, Hazrat-bal, \\ 190006, India
}

Received 10.07.2020

Accepted 29.10.2020

\begin{abstract}
Friction losses and wear losses are the main failure reasons in the internal combustion (IC) engine components i.e., cylinder liner and piston. So, it demands lightweight self-lubricating low friction and wear-resistant materials to increase the efficiency and reduce the emission issue of the IC engine. In this concern, tribological tests are performed on self-lubricating aluminium composites samples reinforced with 6 wt. $\%$ of $\gamma-\mathrm{Al}_{2} \mathrm{O}_{3}$ and Graphene Nano Platelets (GNP) with varying concentration $(0.5$ wt.\% - 5 wt. \%), using ball-on-disc tribo-configuration under dry sliding conditions. The scope of this study is to investigate the anti-friction and anti-wear properties of GNP as reinforcement in the hybrid nanocomposite. The hybrid nanocomposite samples are fabricated using Spark Plasma Sintering (SPS) fabrication route. From the results, it is reported that friction and wear reduction percentage is $37.43 \%$ and $51.64 \%$, respectively for the hybrid nanocomposite with $5 \mathrm{wt}$. \% GNP. It is attributed to the inclusion of GNP, which reduces the Coefficient of Friction (COF) and improves wear resistance of the composite significantly.
\end{abstract}

Keywords: friction; wear; self-lubrication; nano aluminium matrix composite.

\section{Introduction}

The automotive industry now seeks lightweight and self-lubricating hybrid composites to reduce vehicle weight; to improve fuel efficiency as well as to reduce $\mathrm{CO}_{2}$ emissions into the atmosphere, and to increase the system's overall lifetime durability [1]. Gradually, the implementation of lightweight composites substituted the use of gray cast iron in IC engine parts. Traditionally used gray cast iron has a superior wear resistance compared to traditional aluminium alloys that promote the development of new hybrid composites that can overcome such traditional aluminium alloys [2]. These hybrid

${ }^{*}$ Corresponding author: Pranav Dev Srivyas, devpranav.srivyas_17@nitsri.net 
composites have enhanced mechanical and wear performance that enables them to find applications in the engine block, cylinder liner, and pistons in internal combustion (IC) engines [3]. As the automakers have moved from cast iron to aluminium for weight reducing purposes, replacing cast iron with aluminium for engine cylinder blocks and liner has the ability for a sizeable reduction in weight, as much as $45 \%$ for gasoline engines [4]. Therefore switching to aluminium for cylinder blocks has created the need for surface engineering technologies capable of overcoming these tribological function deficiencies. Historically, the solution is to sleeve the aluminium cylinder bores with cast iron to satisfy the specified surface characteristics. Cast iron liners are low-cost, longlasting, and easy to fabricate, which can be the important criteria for mass production.

Now, the automakers are looking into new methods or resurrecting old solutions to growing vehicle fuel economy. Moving far from cast iron sleeves offers the automakers and possibility to solve some of the secondary issues of the inherent disadvantage in weight, thermal conductivity, differential thermal expansion, and recyclability in comparison to the ability opportunity materials [5]. The distinct thermal expansion coefficients of the grey cast iron and the aluminium cylinder block material can cause the deformation of the liner and also lead to heat transfer problems if the liner disengages from the engine block. Particularly the deformation of the liner results in an expanded oil and fuel consumption and increasing emissions. In order for the cylinder block and liner to meet these functional requirements, the engineering materials used to manufacture the product must possess high strength, modulus of elasticity, wear resistance, scuffing resistance, and corrosion resistance. The material of the cylinder liner must be of sufficient hardness to resist the wearing of the piston as it slides up and down on the cylinder wall. Two of the most important material characteristics that are needed for the cylinder liner surface are wear and scuffing resistance [6]. Wear is erosion or displacement of material from its original position on a solid surface performed by the action of another surface [3]. Scuffing is the phenomenon characterized by a mass movement of surface elements to form linear scratches and local welds on surfaces in relative motion.

Wear and scuffing occur on the cylinder liner surface when the lubrication conditions deteriorate. Another important requirement for cylinder liner material is its coefficient of friction. Friction between the cylinder block surface and the piston rings has a major impact on the efficiency of an automobile's powertrain. Friction accounts for a loss of over $40 \%$ of the total vehicle power [5]. Over half of that power loss can be attributed to the frictional loss between piston rings and cylinder liners. Therefore in order for the alternative to be a viable option for replacing cast-iron liners, the more it can reduce the frictional loss between the cylinder liner and the piston ring. The aluminium alloys used for cylinder liner demand strictly controlled characteristics and mechanical properties to meet the functional requirements in modern automobiles.

Hybrid AMNC's are reinforced with two or more distinct reinforcements so that their results had been preferred to those of the separate parts used alone. Metal matrix hybrid composites reinforced with ceramic particles as primary reinforcement and solid lubricant as secondary reinforcement are innovative materials for multiple structural applications owing to outstanding custom characteristics. Hybrid metal matrix nanocomposites (HMMNC's) are mixed with metallic alloy properties (toughness and ductility), hard-phase ceramics (high strength and high modulus), and durable lubricants (low shear strength and self-lubricating) result in excellent composite properties [4-6]. 
The use of aluminium alloy as matrix represents the class of metal matrix composite, which possess properties like low density, high strength, good stiffness, high fatigue resistance, good wear resistance, and low coefficient of thermal expansion [7-9]. Due to this, in the present study eutectic phase binary Al-Si alloy used as matrix material, which is lightweight matrix material. The ceramic material, which is used as primary reinforcement, is much denser than the matrix material. The addition of this primary reinforcement increases the hardness of the composite material [11-13].

The ceramic reinforcement possesses superior strength than any other type of reinforcement. Because of this fact, they are used as a primary reinforcement for the development of hybrid advanced composites. However, the inclusion of the secondary reinforcement adds edge properties to the material. To get the optimum properties optimum wt. \% of the reinforcement is added. Furthermore, an introduction to the new feature improves the performance of the hybrid composite. The primary feature is to reduce the weight of the composite and secondary to provide superior physical, mechanical and tribological properties [14-15]. Many types of research have been reported on the use of $\mathrm{Al}$ alloys and aluminium matrix composites, but a few are reported on the tribological behaviour of HMMNC's [16-22]. Pedersen and Arnbery [16] reported that the presence of Si in the Al-Si alloy improves the fluidity of the alloy, which results in a good cast. It is also reported that the hard Si phase is dispersed in the form of eutectic phase, which improves the mechanical as well as tribological behaviour of the alloy. Roy et al. [17] from his research reported that increased silicon content beyond the eutectic composition in the Al-Si alloy should have technological interest and can be used in various structural applications. Elmadagli et al. [18], in their study, compared the silicon morphology with the wear rate/ wear performance of Al-Si alloy. After the study, it is reported that the silicon morphology influences the transient load as well as the wear rate of the alloy. Gurcan and Baker [19] studied the wear behaviour of $\mathrm{Al} / \mathrm{SiCp}, \mathrm{Al} / \mathrm{Al}_{2} \mathrm{O}_{3}$ fiber, and $\mathrm{Al}\left(\mathrm{Al}_{2} \mathrm{O}_{3}\right.$ Fiber $\left.+\mathrm{SiCp}\right)$ show better wear resistance as compared to all other composition as well as monolithic Al. Song and Han [20], in their study, investigated the wear resistance with respect to the carbon fiber concentration of $\mathrm{Al} / \mathrm{Al}_{2} \mathrm{O}_{3} /$ Carbon hybrid composite.

It is reported that the hybrid composite contains carbon as secondary reinforcement shows better wear resistance than that of $\mathrm{Al} / \mathrm{Al}_{2} \mathrm{O}_{3}$ composite. Yazdani et al. [21] experimentally studied the tribological performance of hot-pressed $\mathrm{Al}_{2} \mathrm{O}_{3}$ and $\mathrm{Al}_{2} \mathrm{O}_{3}$ composite with hybrid content of CNT \& GNP under different tribological conditions. It is reported that the composite with $0.5 \mathrm{wt}$. \% Graphene Nano Platelets (GNP) reduces COF. Up to $23 \%$ reduction in $\mathrm{COF} \& 70 \%$ reduction in wear rate compared to base composition. The hybrid composition with $0.3 \mathrm{wt}$. \% of GNP \& $1 \mathrm{wt}$. \% of CNT shows even better results with a reduction in wear rate by $86 \%$. It is reported that the reduction in the wear rate is attributed to the tribo-film formation on the damaged surface. Llorente et al. [22] studied the wear behaviour of SiC/Graphite composite under dry conditions with silicon nitride as a counter-body. It is reported that the inclusion of GNP in the SiC reduces the wear rate as compared to monolithic SiC. Mostly, studies on the composites are focused on the type of the reinforcements, such as the mixture of fiber/whiskers and whiskers/ particles, but the literature in the hybrid composites with nanoparticles is very rare. The present study highlights the characteristics of HMMNC's developed by SPS. SPS is non-conventional, economical, and highly productive, where the fabrication route provides samples with reduced scrap (cost-effective). The potential of secondary 
reinforcement for the development of HAMNC'S along with the application area. Further, the influence of reinforcement content and tribological conditions/ parameters on the material properties has also been reported in this study.

\section{Material Selection and Sample Preparation}

Eutectic Al alloy (composition: Silicon $-10.244 \%$; Iron $<0.8 \%$; Copper $<0.3 \%$; Zinc $<0.2 \%$; Manganese $<0.15 \%$; Magnesium $<0.1 \%$; Aluminium - Bal.) powder of size $60-70 \mu \mathrm{m}$, and density $2.66 \mathrm{~g} / \mathrm{cm}^{3}$ is used as the matrix material in this experimental study. SEM \& EDS analysis of the base matrix alloy is represented in Fig.1. The matrix material is reinforced with 6 wt. $\%$ of $\gamma-\mathrm{Al}_{2} \mathrm{O}_{3}$ nanoparticles (density $3.95 \mathrm{~g} / \mathrm{cm}^{3}$ ) (APS20nm; purity 99.99\%) and GNP (density $2.3 \mathrm{~g} / \mathrm{cm}^{3}$ ) (Multilayer 2-6 nm; purity $99.999 \%$ ) with carrying wt. $\%(0.5 ; 1 ; 2 ; 3 ; 4 ; 5$ wt. \%). TEM images of the nano aluminium oxide reinforcement and GNP reinforcement are represented in Fig. 2 a and b, respectively. All these powdered materials are procured from Intelligent Material Pvt. Ltd. India. For mixing and blending of the matrix powders with reinforcements ultra-sonication followed by ball milling is done. However, it is very troublesome to incorporate GNP particles into the matrix material. Ultra sonication is considered as the most powerful techniques to disperse nanoparticles in the matrix as well as in the lubricants. To disperse the GNP uniformly into the aluminium silicon matrix, combination of liquid state ultra-sonication and solid-state SPS is used. Ultra sonication followed by solid state stirring can successfully incorporate and disperse the GNP into metal matrix to fabricate metal matrix composite [23-24]. The GNP powder is sonicated with ethanol with varying concentrations for 3 hours in order to disperse the GNP uniformly in the ethanol. After that nano $\gamma-\mathrm{Al}_{2} \mathrm{O}_{3}$ is added to the ethanol-GNP suspension and sonicated for 1 hour. Further, the matrix alloy is finally added in that suspension and probe sonication is performed for 2 hours. After the probe sonication, the suspension is then ball milled in high energy planetary ball mill (Fritsch, Pulverisette, 5 Classic) at $240 \mathrm{rpm}$ for 12 hours with a pause of 15 minutes every 2 hours in a Silicon Nitride vial with powder to ball ratio 1:10. Silicon Nitride balls of $10 \mathrm{~mm}$ are used in this blending procedure. The suspension of eutectic Al-Si alloy -6 wt. $\% \gamma-\mathrm{Al}_{2} \mathrm{O}_{3}$ and GNP with varying weight percentages are then dried in a vacuum rotatory evaporator at $50{ }^{\circ} \mathrm{C}$ for 3 hours/sample and then further in a vacuum oven to remove the existing moisture content. The dried powder samples are placed in the glove box to avoid atmospheric contamination and oxidation of the composite powder samples.
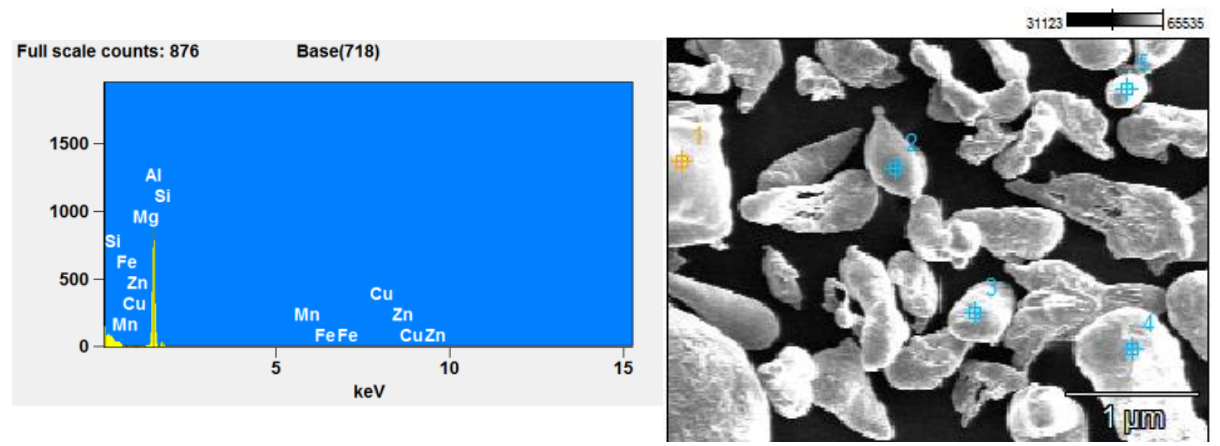

Fig. 1. SEM \& EDS micrographs images of eutectic Al-Si powder [5]. 


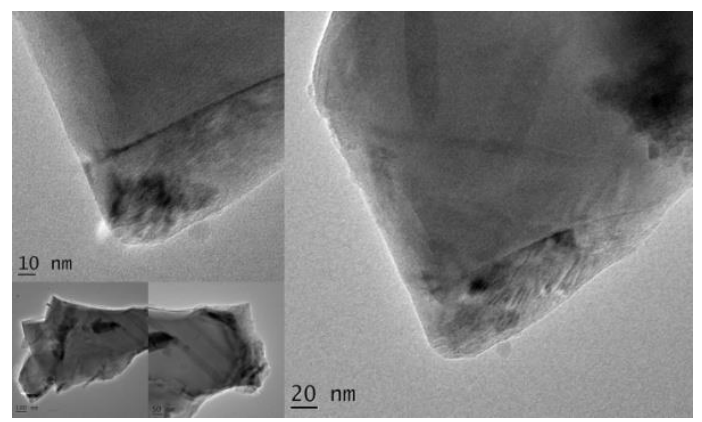

(a)

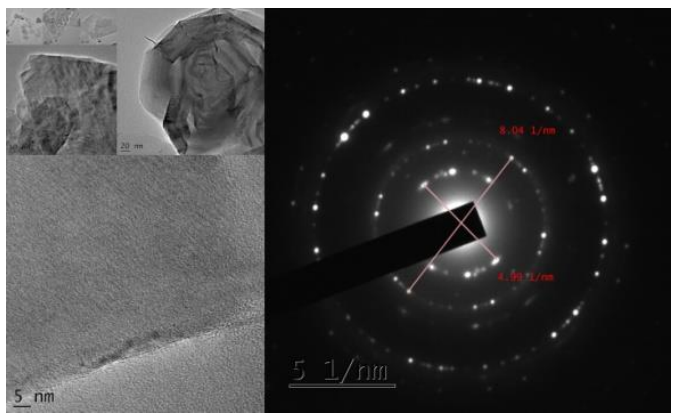

(b)

Fig. 2. (a) TEM images of $\gamma-\mathrm{Al}_{2} \mathrm{O}_{3}$, and (b) TEM images of GNP [5].

After mechanical blending, consolidation is done by using non-conventional Spark Plasma Sintering (Dr. Sinter SPS-625, JAPAN). Uniaxial pressure and pulsed DC are applied hand by hand to consolidate and sinter the powder sample in a controlled atmosphere in a graphite die. The graphite sheet is placed in the die, and then the powder is poured in the die of $30 \mathrm{~mm}$ diameter. A thin rhombic BN spray layer made on the punched surfaces helps in the easy removal of samples after fabrication. The hybrid samples are fabricated at the temperature of $500^{\circ} \mathrm{C}$ with applied pressure $50 \mathrm{MPa}$, and heating rate $100^{\circ} \mathrm{C} / \mathrm{min}$ in an argon atmosphere. The temperature is measured using $\mathrm{K}$ type thermocouple. Sintered samples are grinded using $(220 ; 400 ; 600 ; 800 ; 1000 ; 1200 ; 1500 ; 2000)$ grit size silicon nitride emery paper followed by polishing with aerosol spray/diamond paste $(5 \mu-0.25 \mu)$ on velvet cloth for mirror polished surface. A high dense and compact sample is acquired using the SPS fabrication route at low temperature. The theoretical, practical, relative density, and porosity content enlisted in Table 1. below. 
Table 1. Theoretical and practical density comparison with respect to reinforcement weight percentage.

\begin{tabular}{|c|c|c|c|c|}
\hline $\begin{array}{l}\text { Composition } \\
\text { [reinforcement wt. \%] }\end{array}$ & $\begin{array}{l}\text { Theoretical } \\
\text { density } \\
\left(\mathrm{g} / \mathrm{cm}^{3}\right)\end{array}$ & $\begin{array}{l}\text { Practical } \\
\text { density } \\
\left(\mathrm{g} / \mathrm{cm}^{3}\right)\end{array}$ & $\begin{array}{l}\text { Relative } \\
\text { density (\%) }\end{array}$ & $\begin{array}{l}\text { Porosity } \\
\text { content }(\%)\end{array}$ \\
\hline $\begin{array}{l}\text { Hybrid composition } 1 \\
\text { [Al-Si }+6 \text { wt. } \% \mathrm{Al}_{2} \mathrm{O}_{3}+0.5 \text { wt. } \% \\
\text { GNP] }\end{array}$ & 2.737 & 2.7162 & 99.24 & 0.76 \\
\hline $\begin{array}{l}\text { Hybrid composition } 2 \\
\text { [Al-Si }+6 \text { wt. } \% \quad \mathrm{Al}_{2} \mathrm{O}_{3}+1 \text { wt. } \% \\
\text { GNP] }\end{array}$ & 2.735 & 2.7143 & 99.24 & 0.76 \\
\hline $\begin{array}{l}\text { Hybrid composition } 3 \\
\text { [Al-Si }+6 \text { wt. } \% \quad \mathrm{Al}_{2} \mathrm{O}_{3}+2 \text { wt. } \% \\
\text { GNP] }\end{array}$ & 2.731 & 2.7005 & 98.88 & 1.12 \\
\hline $\begin{array}{l}\text { Hybrid composition } 4 \\
\text { [Al-Si }+6 \text { wt. } \% \quad \mathrm{Al}_{2} \mathrm{O}_{3}+3 \text { wt. } \% \\
\text { GNP] }\end{array}$ & 2.728 & 2.6865 & 98.47 & 1.53 \\
\hline $\begin{array}{l}\text { Hybrid composition } 5 \\
{\left[\mathrm{Al}-\mathrm{Si}+6 \text { wt. } \% \quad \mathrm{Al}_{2} \mathrm{O}_{3}+4 \text { wt. } \%\right.} \\
\text { GNP] }\end{array}$ & 2.727 & 2.6698 & 97.90 & 2.1 \\
\hline $\begin{array}{l}\text { Hybrid composition } 6 \\
\text { [Al-Si }+6 \text { wt. } \% \quad \mathrm{Al}_{2} \mathrm{O}_{3}+5 \text { wt. } \% \\
\text { GNP] }\end{array}$ & 2.724 & 2.6631 & 97.76 & 2.24 \\
\hline
\end{tabular}

\section{Tribological testing and Characterization}

Tribo-test on hybrid nano aluminium composite disc against chrome steel ball (plated with chromium) is performed at room temperature on a Reciprocating Universal Tribometer (R-Tech) represented in Fig.3. The tribological reciprocating test is done as per ASTM G113-05 Standards [25-27]. Tribological testing details are shown in Table 2.

Table 2. Tribological testing details

\begin{tabular}{|c|c|c|c|}
\hline \multicolumn{2}{|c|}{ Tribological parameters } & \multicolumn{2}{|l|}{ Details } \\
\hline \multirow{2}{*}{\multicolumn{2}{|c|}{$\begin{array}{l}\text { Ball on disc tribometer } \\
\text { Counter body }\end{array}$}} & \multirow{2}{*}{\multicolumn{2}{|c|}{$\begin{array}{l}\text { Reciprocating configuration } \\
\text { Chromium plated chrome steel ball (10 } \\
\text { mm diameter) }\end{array}$}} \\
\hline & & & \\
\hline Load test & & Sliding distance test & \\
\hline Variable load & $\begin{array}{l}10 \text { Newton }-80 \\
\text { Newton }\end{array}$ & $\begin{array}{l}\text { Variable sliding } \\
\text { distance }\end{array}$ & $\begin{array}{l}90 \text { meter }-450 \\
\text { meter }\end{array}$ \\
\hline Stroke & $2 \mathrm{~mm}$ & Stroke & $2 \mathrm{~mm}$ \\
\hline Sliding distance & 120 meter & Load & 10 Newton \\
\hline $\begin{array}{l}\text { Reciprocating } \\
\text { frequency }\end{array}$ & $30 \mathrm{~Hz}$ & $\begin{array}{l}\text { Reciprocating } \\
\text { frequency }\end{array}$ & $30 \mathrm{~Hz}$ \\
\hline $\begin{array}{l}\text { Operating } \\
\text { temperature }\end{array}$ & Room temperature & $\begin{array}{l}\text { Operating } \\
\text { temperature }\end{array}$ & Room temperature \\
\hline
\end{tabular}


After each test, the disc and ball are properly cleaned with acetone and dried in a vacuum oven. COF for the different load, as well as the sliding distance, is calculated automatically by the data acquisition system installed in the computer system, which is directly connected to the tribometer with the help of different piezo-electric sensors. The input data details, as well as the output results, are automatically saved in the system. 3D Surface Profilometer is used to measure wear volume for each load and sliding distance test [28-32]. To calculate the specific wear rate, we use equation (i) [33] given below:

$$
W r=\frac{W_{V}}{S D \times L}
$$

where $\mathrm{Wr}$ is specific wear rate, $\mathrm{Wv}$ is wear volume, $\mathrm{SD}$ is the sliding distance, and $\mathrm{L}$ is load.

Roughness studies are made using (R-Tech, USA) 3-D Surface Profilometer on the composite samples, polished surface, as well as on the counter-body. The average surface roughness value for the composite sample is $0.008 \mu \mathrm{m}$, and for counter-body, $\mathrm{Ra}$ value is $0.04 \mu \mathrm{m}$.

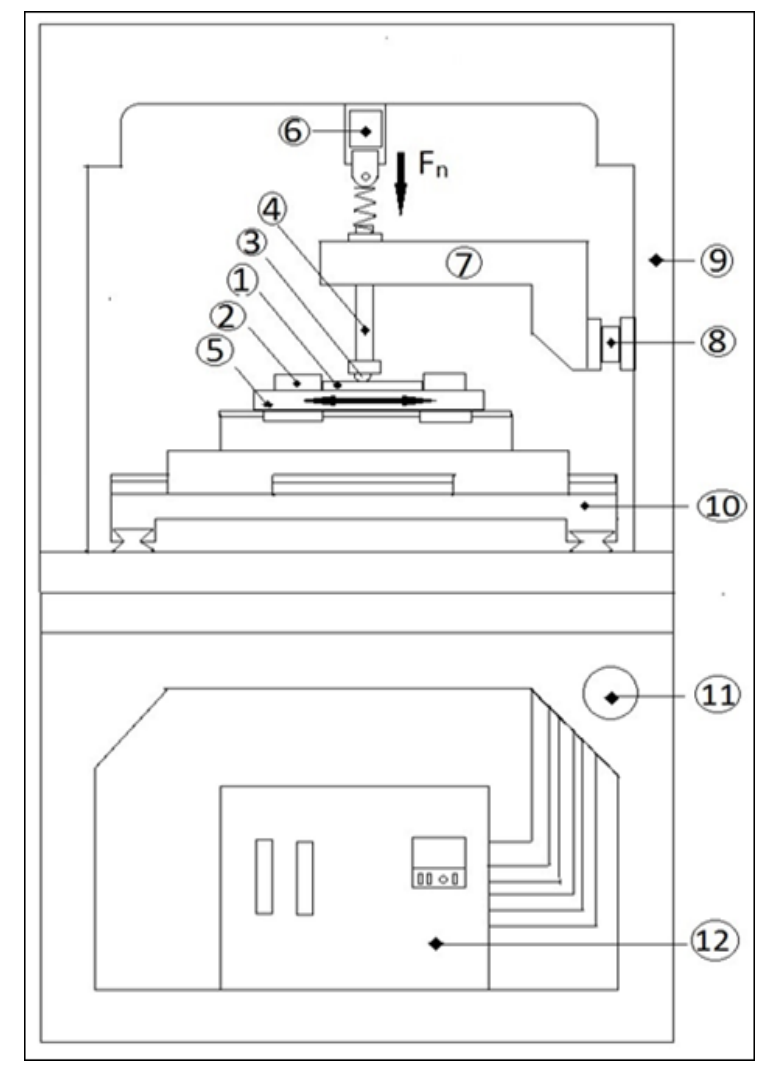

Fig. 3. Schematic diagram reciprocating setup (1) disc sample (2) clamp for disc sample (3) ball specimen (4) ball holder (5)electromagnetic reciprocating drive (6) load actuator (7) loading arm (8) sensor (piezoelectric) (9) supporting frame (10) x-y moving platform (11) emergency button (12) control panel [36]. 


\section{Results and Discussion}

Effect and analysis of load and sliding distanceon Coefficient of Friction:

Variable load test $10 \mathrm{~N}-80 \mathrm{~N}$ are performed in this study with other parameters i.e., frequency $30 \mathrm{~Hz}$, stroke $2 \mathrm{~mm}$, and sliding distance (120 meters) remains constant under dry conditions. Each test is performed thrice to reduce experimental error. Table 3 and 4 represents the COF, wear volume and specific wear rate for a different composite sample at variable load and sliding distance, respectively. COF Results at a variable load and sliding distance for different compositions samples are experimentally obtained from the studies shown Fig.4 and Fig. 5, respectively. Wear volume \&Specific wear rate of all specimens at variable load is shown in Fig. 6 and 7, respectively. Wear volume and specific wear rate of all specimens at the variable sliding distance shown in Fig.8 and Fig. 9 , respectively.

Table 3. COF, wear volume and specific wear rate for composite samples at variable load.

COF for different composite sample at variable load

\begin{tabular}{lllllll}
\hline Load & HC-1 & HC-2 & HC-3 & HC-4 & HC-5 & HC-6 \\
\hline $10 \mathrm{~N}$ & 0.2906 & 0.2687 & 0.2375 & 0.2229 & 0.2028 & 0.1818 \\
$20 \mathrm{~N}$ & 0.1588 & 0.1783 & 0.1745 & 0.17 & 0.1694 & 0.1458 \\
$30 \mathrm{~N}$ & 0.1574 & 0.1652 & 0.16498 & 0.1592 & 0.1528 & 0.1399 \\
$40 \mathrm{~N}$ & 0.1459 & 0.1597 & 0.1587 & 0.1565 & 0.1465 & 0.1322 \\
$50 \mathrm{~N}$ & 0.1428 & 0.1548 & 0.155 & 0.1488 & 0.1329 & 0.1296 \\
$60 \mathrm{~N}$ & 0.1537 & 0.1518 & 0.1526 & 0.1472 & 0.1328 & 0.1291 \\
$70 \mathrm{~N}$ & 0.1547 & 0.1523 & 0.1543 & 0.1482 & 0.1313 & 0.1316 \\
$80 \mathrm{~N}$ & 0.1551 & 0.155 & 0.1547 & 0.1507 & 0.1403 & 0.1345 \\
\hline
\end{tabular}

Wear Volume $\left(\mathrm{mm}^{3}\right)$ for different composite sample at variable load

\begin{tabular}{lllllll}
\hline Load & HC-1 & HC-2 & HC-3 & HC-4 & HC-5 & HC-6 \\
\hline $10 \mathrm{~N}$ & 0.03993 & 0.03877 & 0.03674 & 0.03232 & 0.02977 & 0.03237 \\
$20 \mathrm{~N}$ & 0.04873 & 0.04537 & 0.04325 & 0.03938 & 0.03487 & 0.03895 \\
$30 \mathrm{~N}$ & 0.0555 & 0.04974 & 0.04797 & 0.04177 & 0.03864 & 0.04011 \\
$40 \mathrm{~N}$ & 0.05996 & 0.0534 & 0.04997 & 0.04522 & 0.03991 & 0.04196 \\
$50 \mathrm{~N}$ & 0.0614 & 0.0581 & 0.05193 & 0.04963 & 0.04327 & 0.04896 \\
$60 \mathrm{~N}$ & 0.06782 & 0.06154 & 0.05456 & 0.05117 & 0.04596 & 0.05001 \\
$70 \mathrm{~N}$ & 0.07011 & 0.06613 & 0.05833 & 0.05447 & 0.04833 & 0.05118 \\
$80 \mathrm{~N}$ & 0.07346 & 0.06922 & 0.05957 & 0.05762 & 0.04977 & 0.05556 \\
\hline
\end{tabular}

Specific Wear Rate $\left(\mathrm{mm}^{3} / \mathrm{N} . \mathrm{m}\right)$ for different composite sample at variable load

\begin{tabular}{lllllll}
\hline Load & HC-1 & HC-2 & HC-3 & HC-4 & HC-5 & HC-6 \\
\hline $10 \mathrm{~N}$ & $3.32721 \mathrm{E}-5$ & $3.23042 \mathrm{E}-5$ & $3.06184 \mathrm{E}-5$ & $2.69347 \mathrm{E}-5$ & $2.48045 \mathrm{E}-5$ & $2.69712 \mathrm{E}-5$ \\
$20 \mathrm{~N}$ & $2.03023 \mathrm{E}-5$ & $1.89044 \mathrm{E}-5$ & $1.80195 \mathrm{E}-5$ & $1.64067 \mathrm{E}-5$ & $1.4528 \mathrm{E}-5$ & $1.62294 \mathrm{E}-5$ \\
$30 \mathrm{~N}$ & $1.54162 \mathrm{E}-5$ & $1.38174 \mathrm{E}-5$ & $1.33237 \mathrm{E}-5$ & $1.16015 \mathrm{E}-5$ & $1.07336 \mathrm{E}-5$ & $1.49372 \mathrm{E}-5$ \\
$40 \mathrm{~N}$ & $1.24922 \mathrm{E}-5$ & $1.11256 \mathrm{E}-5$ & $1.04095 \mathrm{E}-5$ & $9.42009 \mathrm{E}-6$ & $8.3148 \mathrm{E}-6$ & $1.11408 \mathrm{E}-5$ \\
$50 \mathrm{~N}$ & $1.02329 \mathrm{E}-5$ & $9.68367 \mathrm{E}-6$ & $8.65461 \mathrm{E}-6$ & $8.27124 \mathrm{E}-6$ & $7.2109 \mathrm{E}-6$ & $8.74254 \mathrm{E}-6$ \\
$60 \mathrm{~N}$ & $9.42009 \mathrm{E}-6$ & $8.54758 \mathrm{E}-6$ & $7.57815 \mathrm{E}-6$ & $7.10631 \mathrm{E}-6$ & $6.38361 \mathrm{E}-6$ & $6.94612 \mathrm{E}-6$ \\
$70 \mathrm{~N}$ & $8.34646 \mathrm{E}-6$ & $7.87228 \mathrm{E}-6$ & $6.944 \mathrm{E}-6$ & $6.48396 \mathrm{E}-6$ & $5.75312 \mathrm{E}-6$ & $6.0927 \mathrm{E}-6$ \\
$80 \mathrm{~N}$ & $7.65231 \mathrm{E}-6$ & $7.21039 \mathrm{E}-6$ & $6.20513 \mathrm{E}-6$ & $6.0021 \mathrm{E}-6$ & $5.18423 \mathrm{E}-6$ & $5.78773 \mathrm{E}-6$ \\
\hline
\end{tabular}


Table 4. COF, wear volume and specific wear rate for composite samples at variable sliding distance.

COF for different composite sample at variable sliding distance

\begin{tabular}{lllllll}
\hline $\begin{array}{l}\text { Sliding } \\
\text { distance } \\
\text { (meter) }\end{array}$ & HC-1 & HC-2 & HC-3 & HC-4 & HC-5 & HC-6 \\
\hline 90 & 0.1917 & 0.1899 & 0.1666 & 0.1617 & 0.1526 & 0.1497 \\
180 & 0.1964 & 0.1926 & 0.1857 & 0.1626 & 0.1555 & 0.1501 \\
270 & 0.1969 & 0.1929 & 0.1854 & 0.1716 & 0.1576 & 0.1512 \\
360 & 0.2036 & 0.1955 & 0.184 & 0.181 & 0.1579 & 0.1521 \\
450 & 0.218 & 0.1997 & 0.1912 & 0.1865 & 0.1579 & 0.1522
\end{tabular}

Wear Volume $\left(\mathrm{mm}^{3}\right)$ for different composite sample at variable sliding distance

\begin{tabular}{lllllll}
\hline $\begin{array}{l}\text { Sliding } \\
\text { distance } \\
\text { (meter) }\end{array}$ & HC-1 & HC-2 & HC-3 & HC-4 & HC-5 & HC-6 \\
\hline 90 & 0.04873 & 0.04537 & 0.04325 & 0.03978 & 0.03487 & 0.02895 \\
180 & 0.05937 & 0.06194 & 0.05701 & 0.06014 & 0.05167 & 0.05001 \\
270 & 0.08353 & 0.0824 & 0.08189 & 0.09104 & 0.09002 & 0.07924 \\
360 & 0.19655 & 0.17689 & 0.16684 & 0.14605 & 0.12174 & 0.09012 \\
450 & 0.31861 & 0.30813 & 0.29846 & 0.2053 & 0.20852 & 0.15407
\end{tabular}

Specific Wear Rate $\left(\mathrm{mm}^{3} / \mathrm{N} . \mathrm{m}\right)$ for different composite sample at variable sliding distance

\begin{tabular}{lllllll}
\hline $\begin{array}{l}\text { Sliding } \\
\text { Distance } \\
\text { (meter) }\end{array}$ & HC-1 & HC-2 & HC-3 & HC-4 & HC-5 & HC-6 \\
\hline 90 & $2.70698 \mathrm{E}-5$ & $2.52059 \mathrm{E}-5$ & $2.40261 \mathrm{E}-5$ & $2.20978 \mathrm{E}-5$ & $1.93706 \mathrm{E}-5$ & $1.60837 \mathrm{E}-5$ \\
180 & $1.64918 \mathrm{E}-5$ & $1.72047 \mathrm{E}-5$ & $1.58368 \mathrm{E}-5$ & $1.67048 \mathrm{E}-5$ & $1.43519 \mathrm{E}-5$ & $1.38917 \mathrm{E}-5$ \\
270 & $1.54681 \mathrm{E}-5$ & $1.52585 \mathrm{E}-5$ & $1.51648 \mathrm{E}-5$ & $1.68599 \mathrm{E}-5$ & $1.66706 \mathrm{E}-5$ & $1.46741 \mathrm{E}-5$ \\
360 & $2.65612 \mathrm{E}-5$ & $2.39041 \mathrm{E}-5$ & $2.2546 \mathrm{E}-5$ & $1.97363 \mathrm{E}-5$ & $1.64508 \mathrm{E}-5$ & $1.21788 \mathrm{E}-5$ \\
450 & $3.54016 \mathrm{E}-5$ & $3.42372 \mathrm{E}-5$ & $3.31626 \mathrm{E}-5$ & $2.28111 \mathrm{E}-5$ & $2.31692 \mathrm{E}-5$ & $1.71193 \mathrm{E}-5$ \\
\hline
\end{tabular}

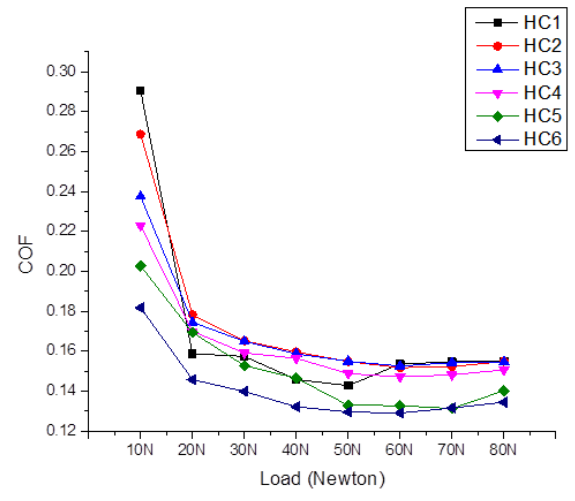

Fig. 4. COF vs. Load.

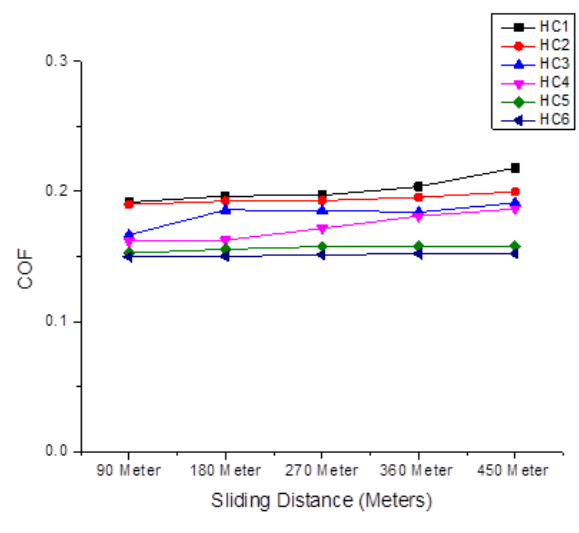

Fig. 5. COF vs. Sliding Distance. 


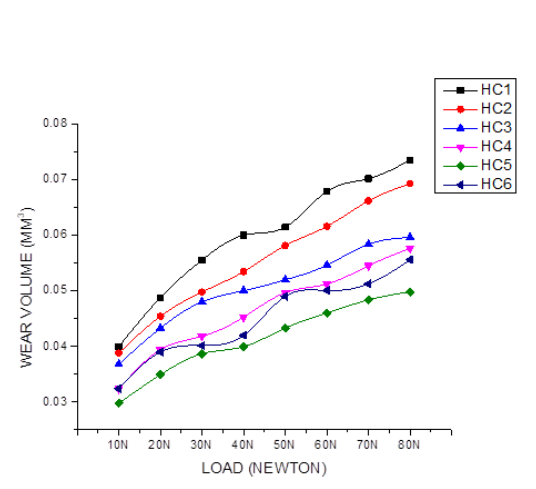

Fig. 6. Wear Volume vs. Load.

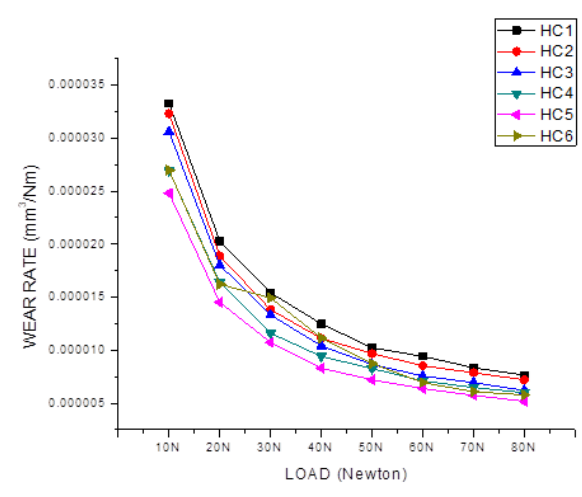

Fig. 7. Wear Rate vs. Load.
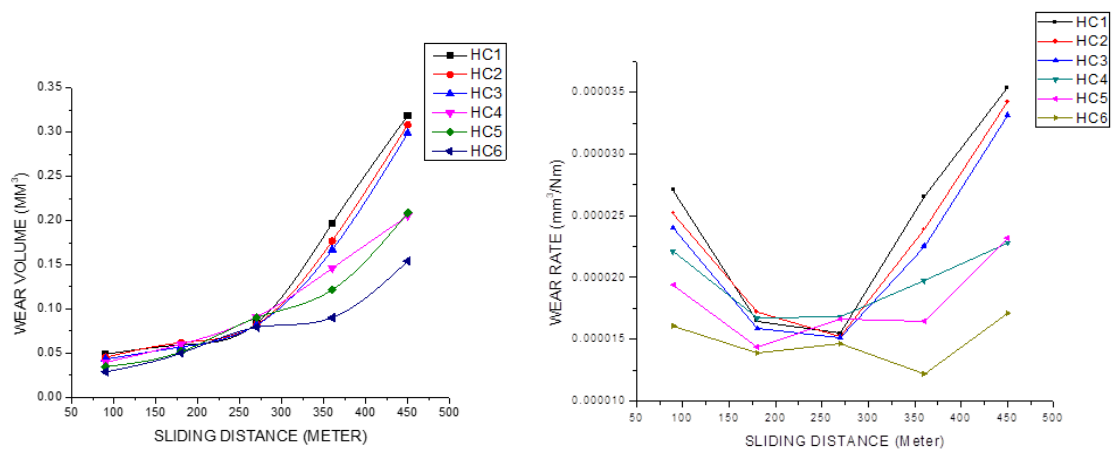

Fig. 8. Wear Volume vs. Sliding Distance. Fig. 9. Wear Rate vs. Sliding Distance.

At the lowest load of $10 \mathrm{~N}$, the highest COF is attained. The high affinity of $\mathrm{Al}$ asperities adheres to counter ball results in the larger frictional traction during sliding at lower load. As the load increases from $10-20 \mathrm{~N}$ and further, the COF decreases linearly [27]. COF for the hybrid composite sample/chromium-plated chrome steel tribopair decreases for the increase in the load from $10 \mathrm{~N}$ to $50 \mathrm{~N}$ applied load under dry sliding conditions. This reduction in the COF is attributed to the secondary GNP reinforcement particles that are present on the wear scar. These GNP particles provide the lubrication mechanism are responsible for the reduction of the COF under $10 \mathrm{~N}-50 \mathrm{~N}$ applied load. Such reduction in the COF is attributed to the grain refinement of the secondary GNP as well as the formation of a protective Graphene oxide layer during tribological testing on the wear scar with increasing load from $10 \mathrm{~N}$ to $50 \mathrm{~N}$. At particular loading conditions, the GNP particles get protrude from the hybrid composite worn sliding surface during the run-in-period. These protrude further act as the ball bearing at the sliding interface helps in the easily sliding as well as improved the load-bearing capacity of the composite, thus reducing COF. The high concentration of GNP particles are also responsible for protuberances generation on the wear scar surface, reducing the opportunity for the matrix material to come in direct contact with the counter-body, ultimately reduces the frictional traction. Another possible mechanism for the reduction in the COF for the hybrid 
composite is the formation of the coherent protective film between the sliding interfaces, which also reduces the friction traction of the tribopair. GNP particles that protrude from the interface during the initial run-in-period do not easily adhere to the counter-body, because of their less affinity to stick/adhere to the counter-body and act as the solid lubricant providing easy sliding [5]. It is found that GNP as solid lubricating between the sample and counter-body form a graphene oxide protective film and get adsorbed on the wear scar. It is attributed to 2D GNP lamellar structure multilayer sheets that provide easy as well as smooth shearing due to weak Van der Waals' forces and acts as an easy slider between the interfaces of the two bodies which result in reducing COF. This protective film has a low shear stress junction, which help in reducing COF and provides smooth sliding [36]. Various previous studies report the formation of the adsorbed graphene oxide layer at the interface, which ultimately reduces the COF and provide the self-lubrication effect. As the applied load increases further from $60 \mathrm{~N}$ to $80 \mathrm{~N}$, there is a minute increase in the COF. It is observed that at these loading conditions, the worn surface obtained is relatively rough, and more rugged grooves are observed compared to lower loading conditions. These rugged grooves and rough scars are attributed to the abrasion wear mechanism, which increases the COF for $60 \mathrm{~N}-80 \mathrm{~N}$ load. At higher load, the GNP particles get fractured, and it will lead to loose in the load-bearing capacity of the secondary reinforcement particles, which further cause the matrix material to come in direct contact with the counter-body. Because of this, $\mathrm{Al}$ asperities come in contact with counter-body, which leads to growth in the COF at the particular loading conditions. The aluminium particles get to adhere to the counter-body, because of the high solubility between the aluminium and steel. As in previous research, it is reported that the high solubility leads to high adhesion, which increases the COF. It is well reported in the previous studies that the actual are of contact at the Nano level (i.e. asperity-asperity contact) has a significant impact on the friction and wear properties of the tribopair. The higher the area of contact of tribopair, higher is the COF. In addition to this, increasing $\mathrm{COF}$ is also attributed to the increasing normal load, which causes surface asperities to shear easily. It is also observed that the frictional properties of the composite are also dependent on the parameters like sliding distance, load as well as surface roughness. The increase in the COF from $60 \mathrm{~N}-80 \mathrm{~N}$ is also attributed to plastic deformation at the subsurface level of the fabricated composite sample. Also, under the high loading conditions, as the sliding begins, the interface temperature is increasing due to friction heat generated. This temperature rise softens the matrix material under the high applied loading condition. This high applied load as well as high interface temperature leads to exceeding the flow strength of the matrix material and further leads to the plastic deformation, which is another possibility for the increase the COF at high loading conditions.

For the sliding distance test the COF initially increases with the increasing sliding distance afterward attain the steady state value of COF. It is observed that during the initial run-in-period, the counter-body and the composite sample come in direct contact, which causes asperity-asperity contact of the tribopair. The direct contact increases the frictional traction of the tribopair leads to increases COF in the initial stage. As the sliding continues, the GNP particles that get protrude leads to a change in the contact from Al-Si matrix / counter-body to GNP/Counter-body, which helps in attaining a steady-state COF for the sliding distance test. This steady-state COF for increasing sliding distance is attributed to the formation of thin conformal antifriction and anti-wear film of graphene oxide, which ultimately reduces the asperities interlocking and stabilize the COF. 


\section{Wear Analysis}

Transition in the wear of the sliding surface is the function of the applied load as well as sliding distance. Wear regime of dry sliding include elastic-plastic mixed-mode contact. The second wear regime is at critical load and is characterized by plastic flow. In this regime, the wear rate is not proportional to the load. Wear regime is characterized by a wear surface that contains deep groove (abrasive grooves), crater wear. Abrasions, as well as delaminating wear, are two other prominent wear in the region I represented in Fig.10. For regime II, plastic deformation is developed in wear surface. Some other wear mechanisms in a dry sliding regime include oxidation wear, metallic wear, transfer layer (tribo-layer), adhesion. Heilmanet. al [34] reported that the transfer layer (tribo-layer) is common in dry sliding wear. They observed that the transfer layer is developed very early in sliding, even before the loss of material. The composition of the transfer layer is the mixture of both sliding surfaces. This type of wear mechanism is neglected by both the wear mechanism of region I. Rice et al. [35] in their study characterizing three zones of the sliding body subjected to wear: (a) Zone-3 is the unaffected, un-deformed zone, (b) Zone-2 is the deformed intermediate zone (This zone is $3 / 2$ and $1 / 2$ interface zone. Elastic-plastic mixed deformation is observed.), and (c) Zone-1 include wear surface and contain the mixed counter body and body material as well as oxide layer/tribo-layer/ transfer layer (voids and cracks are formed on this zone surface).
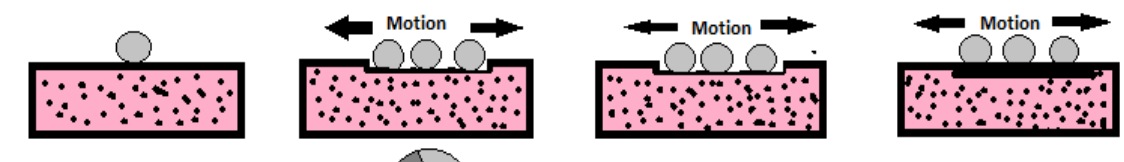

Plastic Deformation

Self Lubricating Protective Film Formation

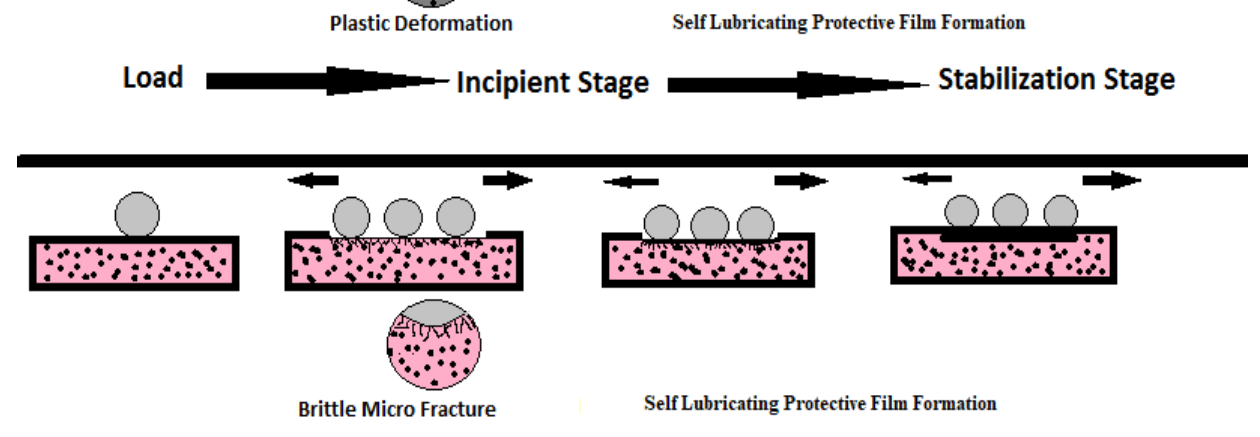

Load

Incipient Stage

Satabilization Stage

\section{Fig. 10. Wear zone analysis.}

Optical and SEM studies for maximum load (80 N) and maximum sliding distance (450 mater) are represented in Fig.11-16. It is observed that mild adhesion, mild abrasion, plastic shear deformation are the most dominant wear mechanism. Formation of tribolayer is also observed in Fig.12 and 15, which prevent direct metal-metal contact act as load-bearing element while tribo-testing. These transfer tribo-oxide layer act as a solid lubricant layer at the interface represented in Fig.13. The concentrate of GNP particles sticks on the surface of the wear scar, which prevents the direct contact of the soft 
aluminium particles and decreases the wear rate. It is observed that the load-bearing capacity of the hybrid composite seems to be more than that of Al-Si alloy. This is because of the load-bearing capacity of reinforcement particles, which limits the plastic deformation of the matrix material. In the initial testing phase, reinforcement particles inhibitors against plastic deformation as well as adhesion wear of the matrix. After the run-in period, the GNP dislodged from the surface and gets mixed with the wear debris. This mechanical mixture of wear debris is represented in Fig.12 and 14. Dislodged GNP particles and matrix material gets lodged in the craters act as a load-bearing element. Rugged grooves are observed on the composite sample, which gives evidence of abrasion by hard asperities. Scratching and grooves appear in the hybrid composite sample represented in Fig.12 - 14. The dark surface in the optical micrographs is due to the thin layer of fine oxides particles. At low $(10 \mathrm{~N})$ applied to load, continuous grooves with fatigue crack are observed in Fig.11, which indicates the removal of material because of the abrasion mechanism. At load $50 \mathrm{~N}$ worn surface reported plastic yielding is reported. Abrasion and delaminating wear are reported at $50 \mathrm{~N}$ load. It is also observed that the near theoretical density less surface porosity is achieved due to SPS, and a good interface between reinforcement and matrix results in lower specific wear of the fabricated samples. The strong interfacial strength between the matrix and reinforcement results in high strength and hardness because of improved load transfer from matrix to reinforcement.

SEM and optical micrographs analysis confirms the formation of the thin film on the disc surface represented in Fig.15. Due to this protective film formation, the asperityasperity contact reduces which depends upon the thickness of the film formation and decreases the adhesion as well as ploughing wear mechanism. Asperities are the actual contact between the mating surfaces at localized/individual points. Mild adhesion, slight transfer of material at the interface, is reported and confirmed by EDS and Raman analysis. SEM and optical analysis reveal the formation of strong oxides layer formed on the wear scar at a sliding distance (360 meters) prevent direct metal contact and reduce the wear of the material which further plastically deformed at a higher sliding distance (450 meters). The protruded wear debris particles reattach to the matrix material due to high ductility of the matrix material, which further leads to form high oxide worn layer on the scar zone, further act as the low shear stress lubricating junction act as the solid lubricating (self-lubricating) interface represented in Fig.16. These fragments particles carry the load while tribo-testing and further leads to the smooth surface of the wear scar interface represented in Fig.16. Plastic deformation at high load conditions further increases the strength of the mating surface as the grain and debris (Mechanical Mixed Layer) are work-hardened at the sub-surface while continuous testing. Thus improve the wear rate resistance performance of the hybrid composite under dry sliding conditions. The interaction of the tribopair has modified further for Al-Si/Counter-body to GNP/Counter-body tribopair which significantly reduces the material loss and wear rate. The fragments due to the plastic deformation act as the third body between the interfaces of the material performed two basic mechanisms: one leads to lubrication effect, and the other is the load-bearing element represented in Fig.14. Mild adhesion, mild abrasion, and delamination (Fig.15) are the dominant wear mechanisms for the hybrid composite samples. SEM and optical micrographs give evidence of mild adhesion, plastic deformation, and shear deformation of the self-lubricating junction, which reduces the 
wear rate of the tribopair. The interface surface observed by SEM is smooth, but, still, some obvious grooves and scratches are formed on the scar zone.

Roughness and wear scar texture studies are done on the hybrid composite samples represented in Fig.11 - 16. From the studies, it is observed that a smooth uniform graphene oxide protective film / tribo-layer is formed, which plays a major role in the reduction of wear, $\mathrm{COF}$ and wear scar roughness. Texture profile and roughness indicates that the wear of the material occurs in the initial phase with further formation of a protective layer. For sliding distance conditions, the roughness value has less impact on the wear scar of material. The roughness of the scar on the composite surface decrease with increased GNP concentration, which helps to determine that the graphene forms a protective smooth layer and reduces roughness value. It is observed that the reduction in roughness value seems to reduce the wear damage on the contacting surface. Further, a load test on the higher graphene concentration sample composite leads to reduced roughness. 3D surface morphology results of the wear scar indicate that GNP particles lead to smooth surface of the wear scar by reducing the surface roughness as the scar zone is notably reduced with increasing GNP concentration.
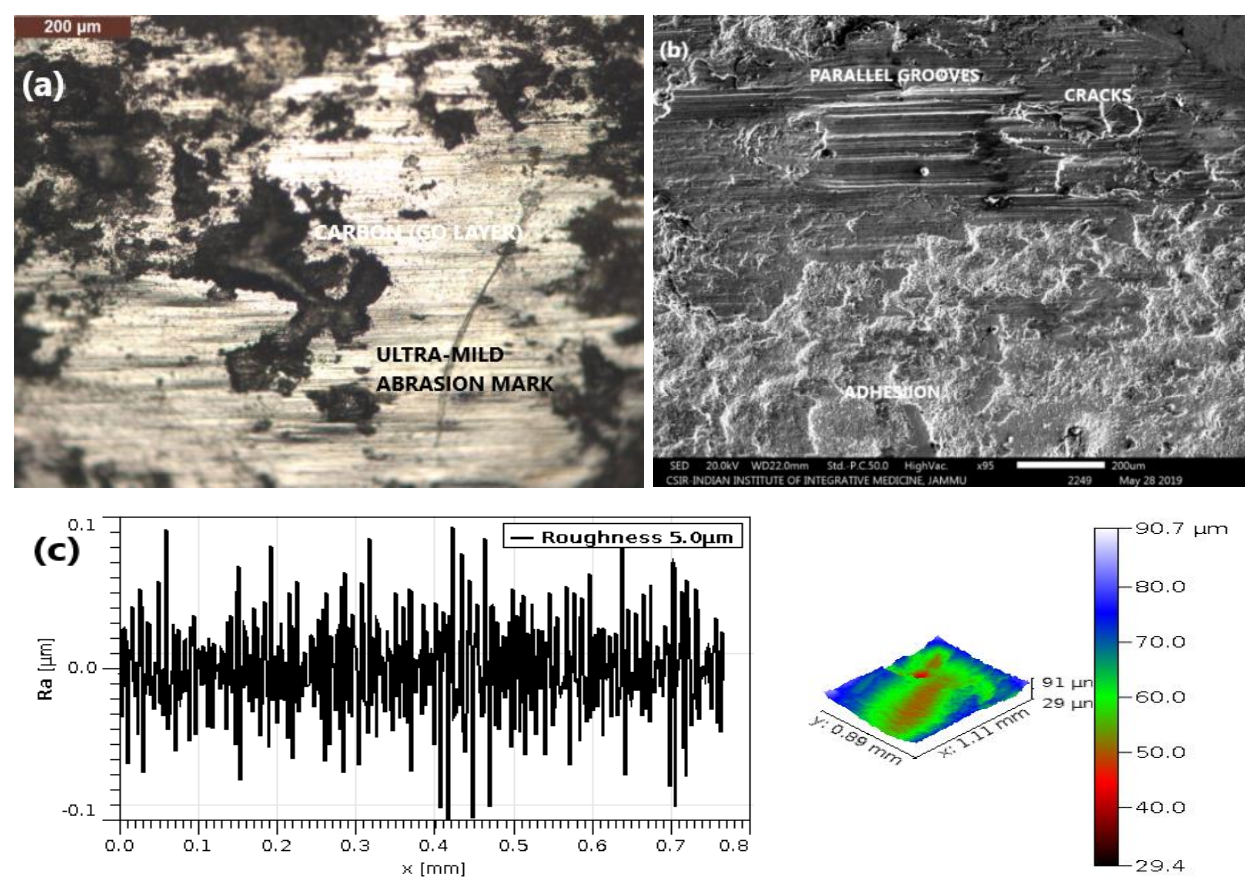

Fig. 11. Optical (a), SEM (b) and 3-D Surface wear micrographs (c) for hybrid composition 1. 

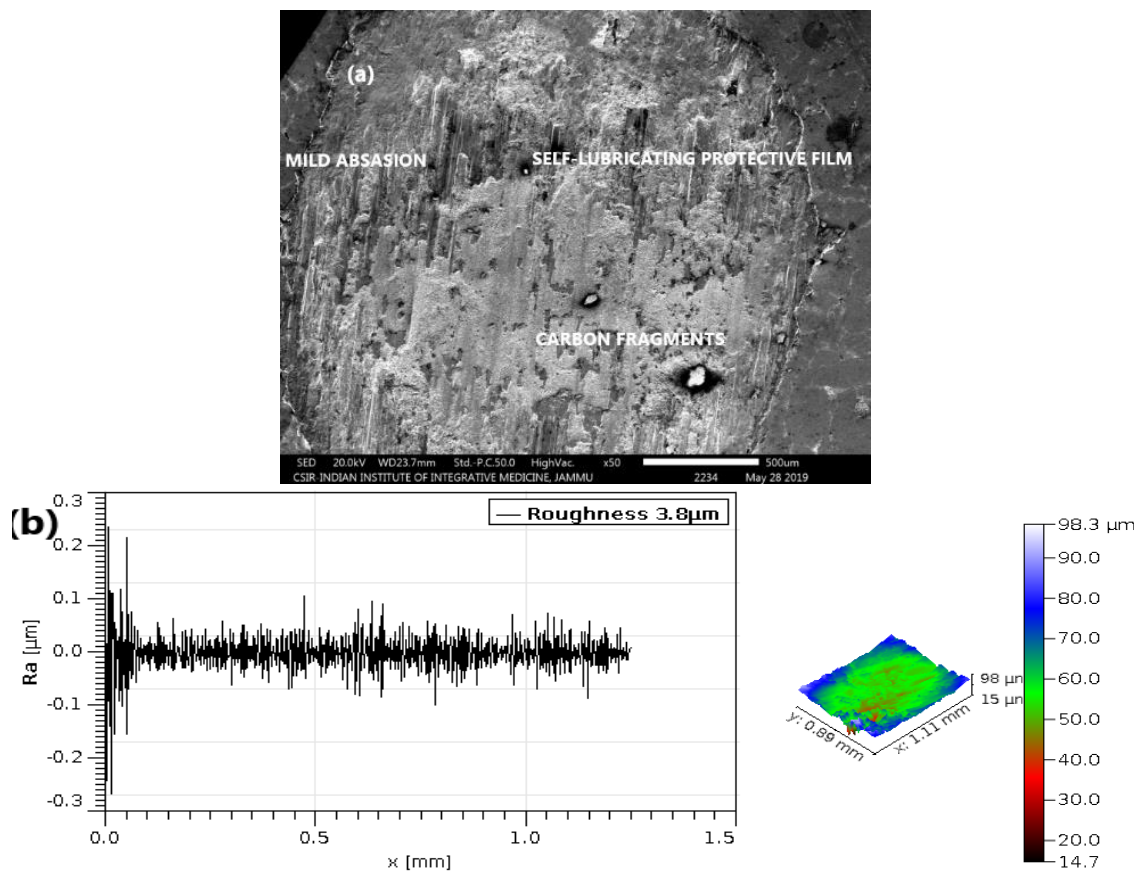

Fig. 12. SEM (a) and 3-D Surface wear micrographs (b) for hybrid composition 2.
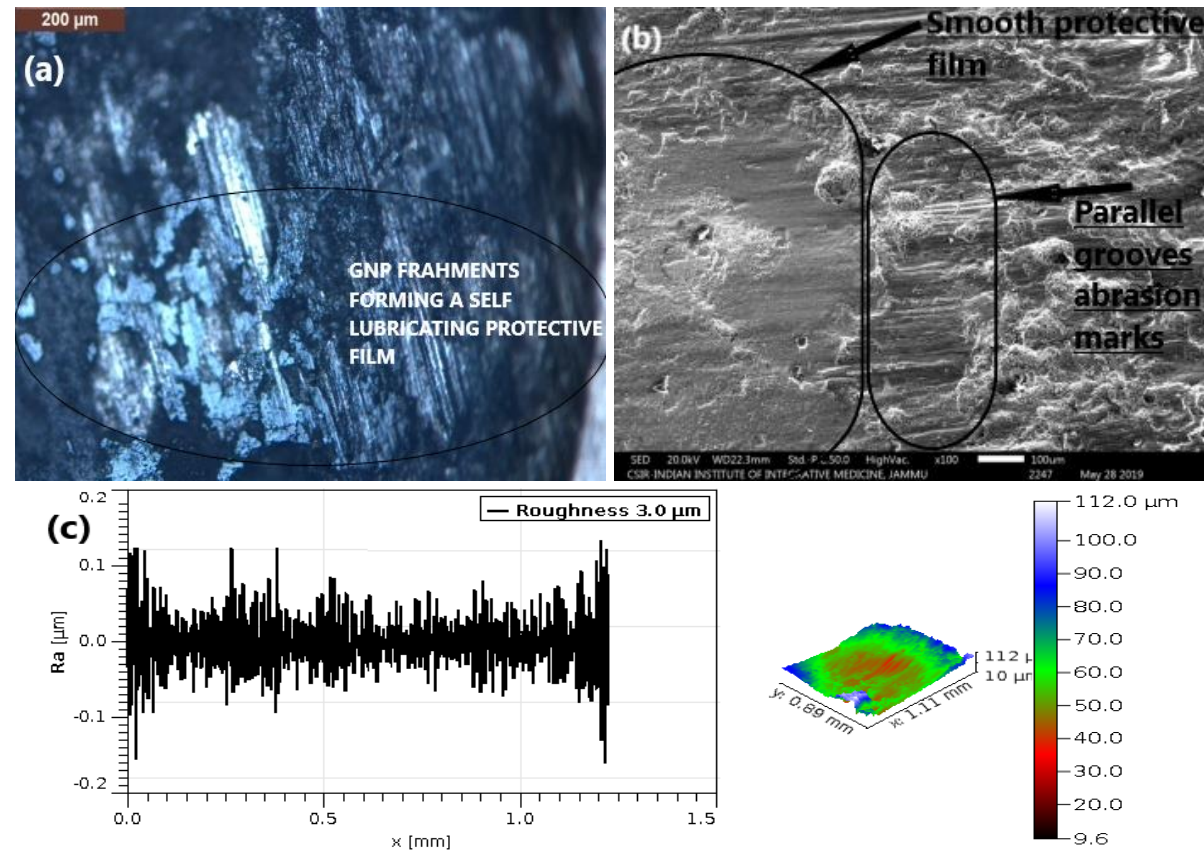

Fig. 13. Optical (a), SEM (b) and 3-D Surface wear micrographs (c) for hybrid composition 3. 

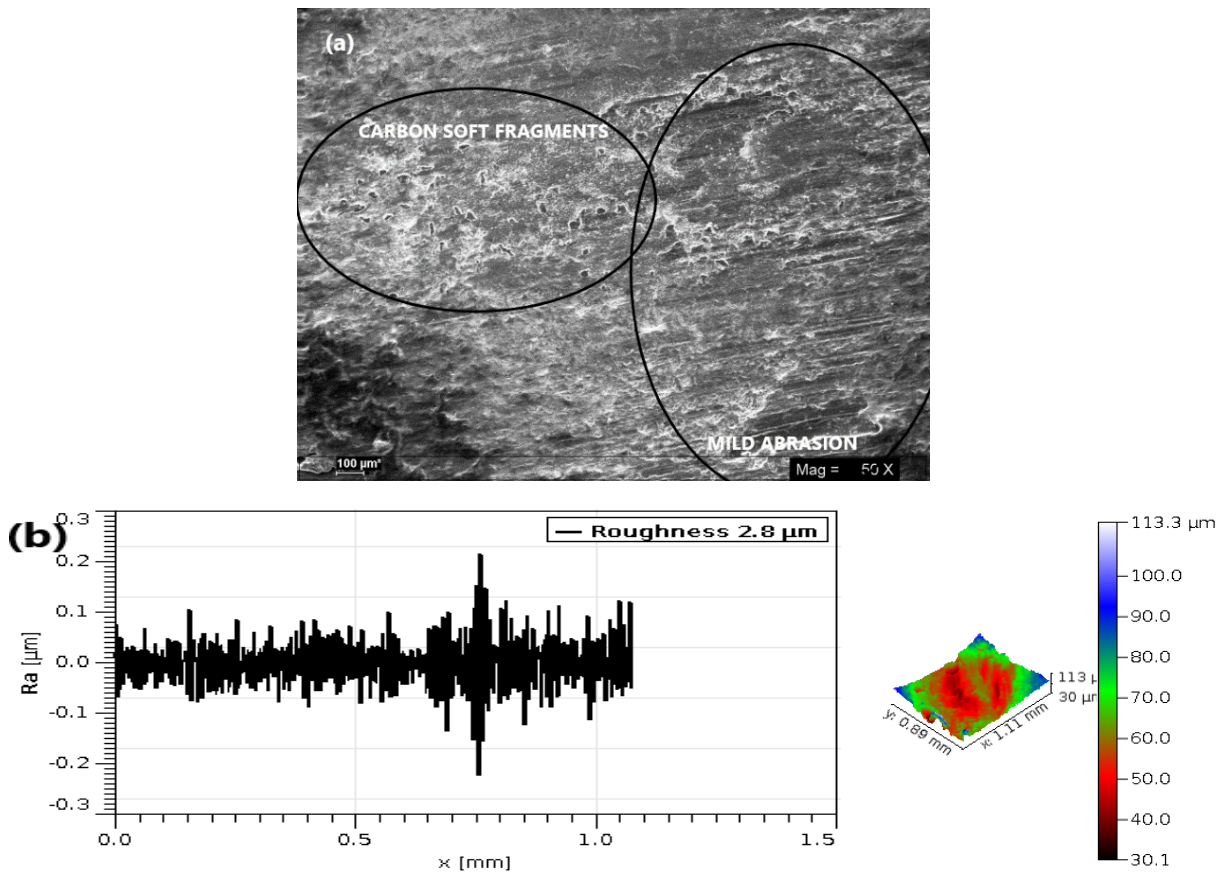

Fig. 14. SEM (a) and 3-D Surface wear micrographs (b) for hybrid composition 4.
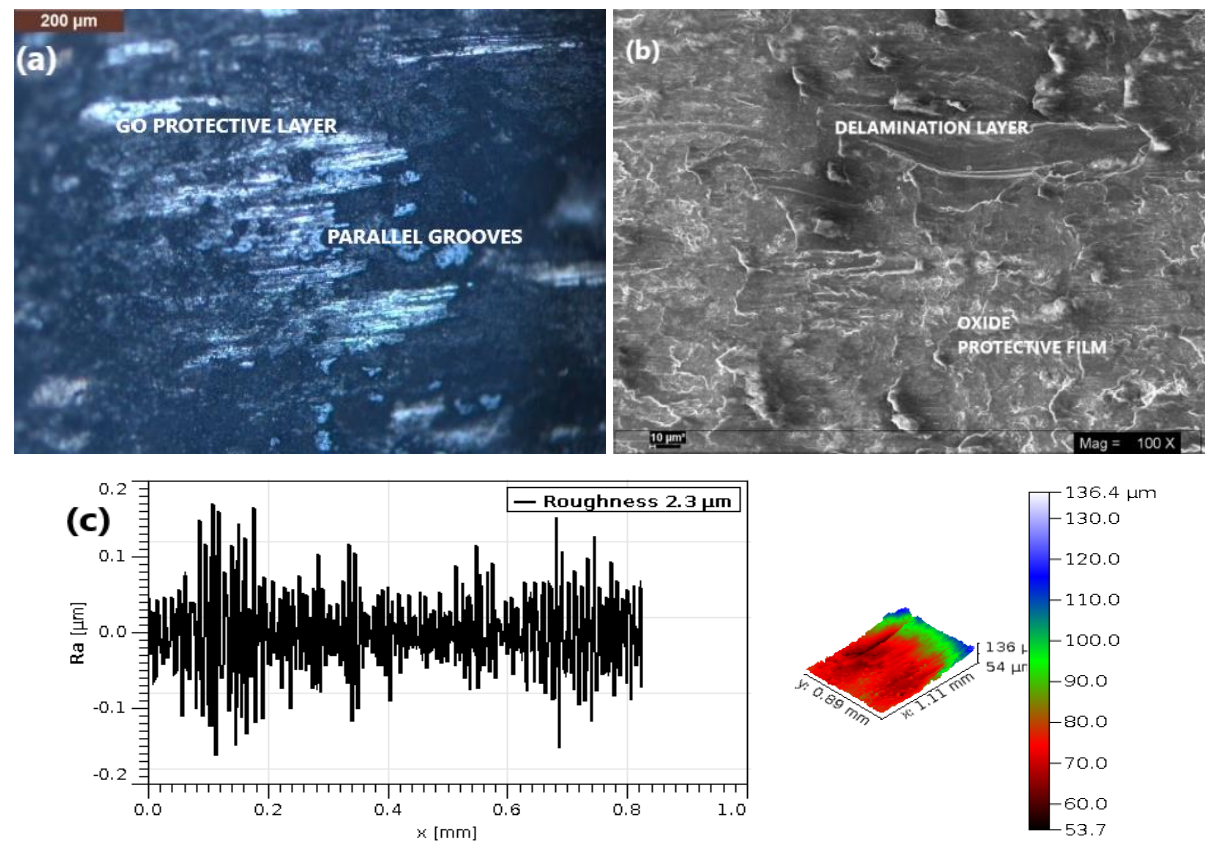

Fig. 15. Optical (a), SEM (b) and 3-D Surface wear micrographs (c) for hybrid composition 5. 

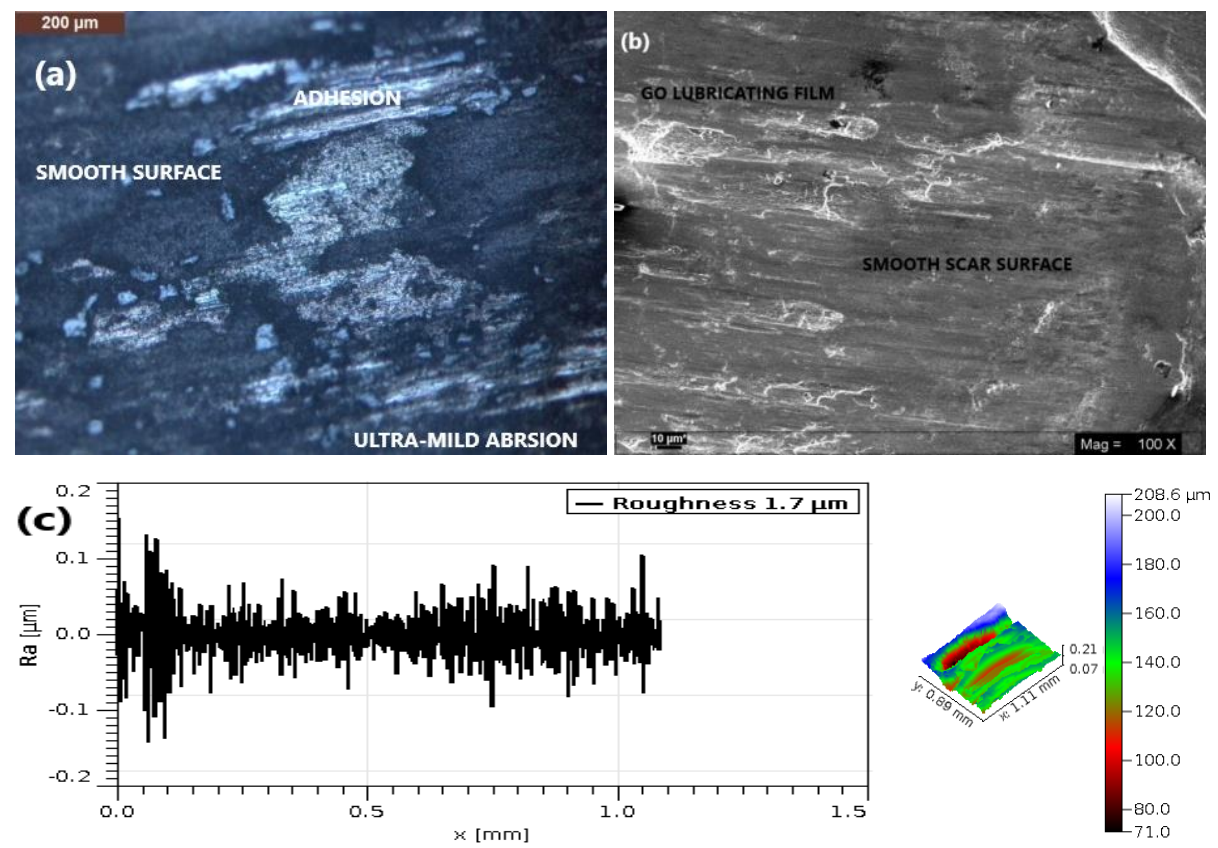

Fig. 16. Optical (a), SEM (b) and 3-D Surface wear micrographs (c) for hybrid composition 6.

EDS analysis reveals the formation of graphene oxide film as well as the presence of Si particles on the wear scar. EDS analysis confirms the presence of carbon, oxygen, silicon element high content on the wear scar, which is evident to conform the formation of graphene oxide protective layer on the scar zone, represented in Fig.17. Negligible material loss, as well as adhesion, is reported on the counter-body. Graphene particles get deposited/stacked on the wear scar during the dry sliding reciprocating test. Moreover, graphene particles fill the deep grooves as well as rugged scratches and cover that with the tribo-film. The tribo-film not only bears the load but also prevents the direct contact of the sliding surface. This ultimately enhances the friction and wear properties of the composite hybrid sample.

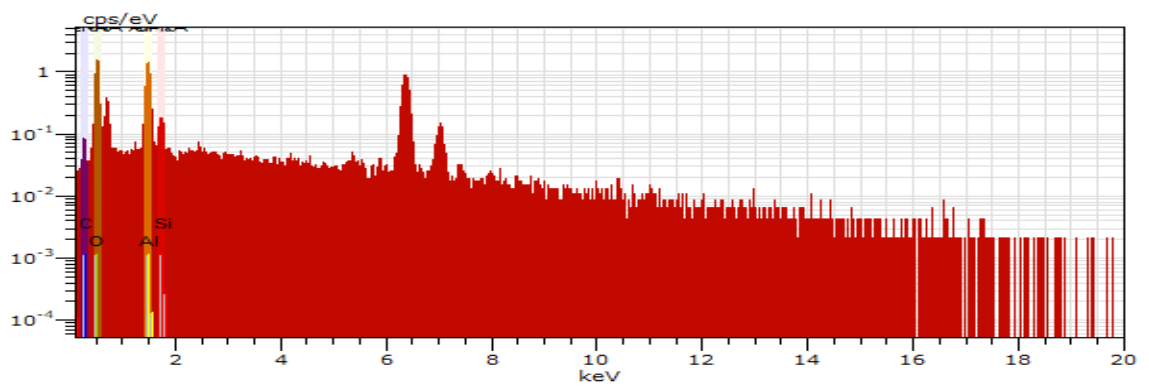

Fig. 17. Analysis of the EDS micrographs on hybrid composite. 
Raman spectroscopy characterization is done on the pure GNP powder sample and also on the wear scar of the hybrid composite sample to characterize carbon material because of the fact that double carbon-carbon bond and conjugated carbon shows high Raman peak intensity. Two bands D $\left(1347 \mathrm{~cm}^{-1}\right)$ and G $\left(1598 \mathrm{~cm}^{-1}\right)$ are reported. Another peak around $2700 \mathrm{~cm}^{-1}$ is reported namely $2 \mathrm{D}$ represented in Fig. 18. The D band in the Raman spectroscopy features $\mathrm{sp}^{3}$ defects in carbon; $\mathrm{G}$ band features plane vibration of $\mathrm{sp}^{2}$ bonded carbon, and 2D band represents layered structure. The analysis confirms the formation of the graphene oxide layer on the wear scar, which ultimately reduces the wear rate and $\mathrm{COF}$.

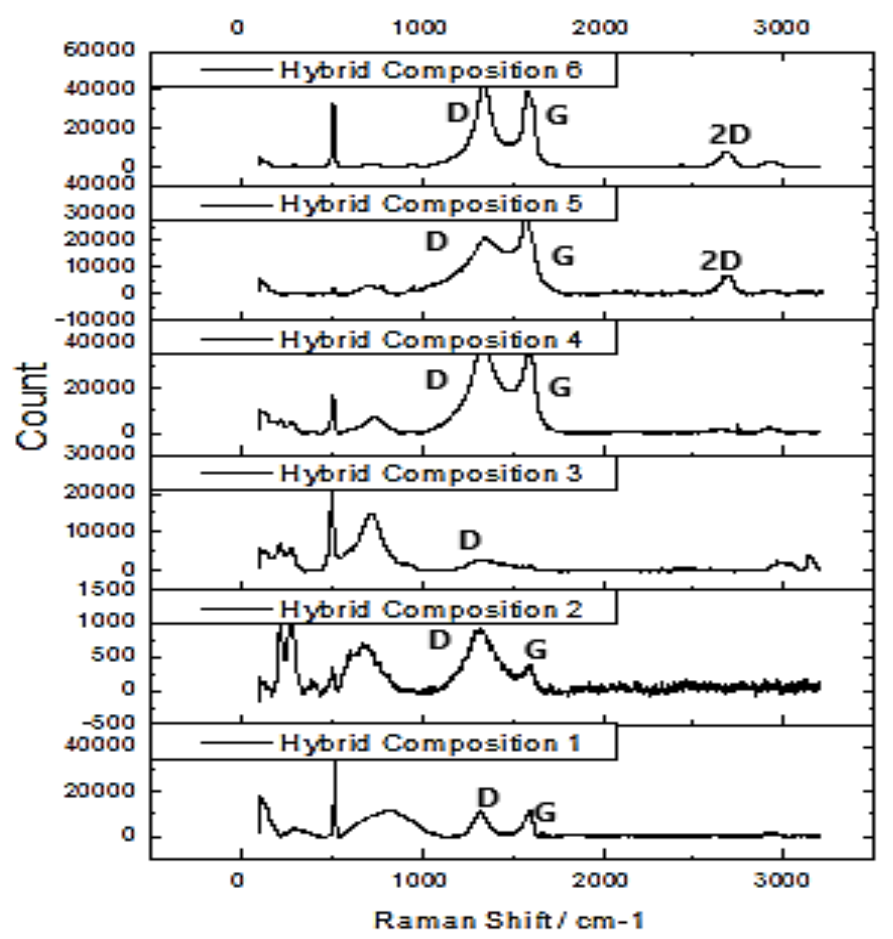

Fig. 18. Raman analysis of the wear scar.

It is observed that GNP particles as secondary reinforcement reduces the wear loss by $51.64 \%$ for composite with 5 wt. \% GNP compared to hybrid composite with $0.5 \mathrm{wt}$. $\%$ of GNP. The reduction in the COF for a similar composite sample is reported to be in the range from $9.24-34.42 \%$ for dry sliding reciprocating conditions. The anti-wear and anti-friction properties of GNP as reinforcement has been clearly exhibited in this study. These results proved that GNP processes excellent tribological properties and shows significant properties even at nano scale. The morphology and size of the GNP particle play a prominent role for friction and wear reduction of hybrid nanocomposite under dry sliding reciprocating conditions. Moreover, the rapid SPS fabrication route also plays a 
significant role in attaining highly dense and compact sample with better mechanical and tribological properties, which results in reducing friction and wear. From the above discussion, it is evident that GNP particles as secondary reinforcement and rapid SPS fabrication route open up a new door for friction and wear reduction of hybrid nanocomposite and could be further used for various industrial as well as automotive applications.

\section{Conclusion}

Friction and wear of the hybrid composite reduced drastically due to the proper dispersion of GNP nanoparticles on the contacting interface. Following are the conclusive points from the present study:

- The use of the liquid state ultra-sonication followed by SPS fabrication route makes it possible to get almost near theoretical dense sample with better dispersion of GNP which also results in low porosity and agglomeration.

- The optimum content of the GNP nanoparticles, which leads to the best tribological properties, is $5 \mathrm{wt}$ \% ( $\left.\mathrm{Al}-\mathrm{Si}+6 \mathrm{wt} . \% \mathrm{Al}_{2} \mathrm{O}_{3}+5 \mathrm{wt} . \% \mathrm{GNP}\right)$ where least $\mathrm{COF}$ and wear volume was reported compared to minimum $1 \mathrm{wt}$. \% GNP concentration.

- Reduction in COF and wear volume of the hybrid composite 6 was reported in the range $13.28-37.43 \%$ and $18.93-24.36 \%$, respectively, compared to the hybrid composite 1 .

- The increase in the surface roughness due to relative sliding of the bodies is decreased by $66 \%$ while using hybrid self-lubricating composite 6 sample compared to hybrid self-lubricating composite 1 sample. Also, there is the reduction in the surface roughness reported with increasing load for a similar composition, which is attributed to enormous contact pressure which crushes or fracture the asperities.

- It is revealed that due to the presence of the graphene particle layer, reduction in the direct asperities contact is reported, which further leads to the smooth surface after the testing.

- Consequently, graphene nanoplatelets in the hybrid composite sample act as self-lubricant material (solid lubricant) endorse the formation of a tribo-layer on the interface.

- GNP along with primary reinforcement nano alumina bears the applied load even at high contacting temperature. This study concludes the positive effect of GNP reinforcement in Al-Si eutectic alloy.

- Moreover, mild adhesion, plastic deformation, and delamination wear are reported in the wear regime. Tribo-layer formation, the load-bearing effect of solid lubricant, is the main positive points that have an impact on the reduced friction and wear of the hybrid composite. 


\section{References}

[1] K.S. Prakash, P. Balasundar, S. Nagaraja, P.M. Gopal, V. Kavimani: Journal of magnesium and alloys, 4 (2016) 197-206.

[2] A. V. Muley, S. Aravindan, I.P. Singh: Manufacturing Review, 2 (2015) 15.

[3] S.C. Tung, M.L. McMillan: Tribology International," 37 (2004) 517-536.

[4] P.D. Srivyas, M.S. Charoo: JurnalTribologi, 25 (2020) 83-101.

[5] P.D. Srivyas, M.S. Charoo: Materials Research Express, 6 (2019) 125702.

[6] P.D. Srivyas, M.S. Charoo: Materials Today: Proceedings, (2020).

[7] D.B. Miracle: Composites science and technology, 65 (2005) 2526-2540.

[8] A. Evans, C. San Marchi, A. Mortensen: Composites in Industry (2003) 9-38.

[9] J. Singh, A. Chauhan: Journal of Materials Research and Technology, 5 (2016) 159-169.

[10] H. Ye: Journal of Materials Engineering and Performance, 12 (2003) 288-297.

[11] M. Chen, T. Perry, A.T. Alpas: Wear, 263 (2007) 552-561.

[12] J.U. Ejiofor, R.G. Reddy: Jom, 49 (1997) 31-37.

[13] K.M. Shorowordi, T. Laoui, A.S.M.A Haseeb, J.P. Celis, L. Froyen: Journal of Materials Processing Technology, 142 (2003) 738-743.

[14] Z. Wang, L. Wu, Y. Qi, W. Cai, Z. Jiang: Surface and Coatings Technology, 204 (2001) 3315-3318.

[15] H. Chandrasekaran, J.O. Johansson: CIRP Annals, 46 (1997) 493-496.

[16] L. Pedersen, L. Arnberg: Materials Science and Engineering: A, 241 (1998) 285 289.

[17] N. Roy, A.M. Samuel, F.H. Samuel: Metallurgical and Materials transactions A, 27 (1996) 415-429.

[18] M. Elmadagli, T. Perry, A.T. Alpas: Wear,262 (2007) 79-92.

[19] A.B. Gurcan, T.N. Baker: Wear, 188 (1995) 185-191.

[20] J.I. Song, K.S. Han: Composite structures, 39 (1997) 309-318.

[21] B. Yazdani, H. Porwal, Y. Xia, H. Yan, M.J. Reece, Y. Zhu: Ceramics International, 41 (2015) 9813-9822.

[22] J. Llorente, M. Belmonte: Journal of the European Ceramic Society, 38 (2018) 3441-3446.

[23] L.Y. Chen, H. Konishi, A. Fehrenbacher, C. Ma, J.Q. Xu, H. Choi, X. C. Li: ScriptaMaterialia, 67 (2012) 29-32.

[24] A.D. Moghadam, E. Omrani, P.L. Menezes, P.K. Rohatgi: Composites Part B: Engineering, 77 (2015) 402-420.

[25] Standard, A. S. T. M. (2010) G133-05.

[26] V. Iliuţă, M. Rîpă, J. Javorova, G. Andrei: IOP Conference Series: Materials Science and Engineering, 174 (2017) 012015.

[27] P. Kumar, M.F. Wani: Journal of Tribology, 140 (2018) 1-19.

[28] A.T. Pérez, A.H. Battez, G. García-Atance, J.L. Viesca, R. González, M. Hadfield: Wear, 271 (2011) 2963-2967.

[29] C. Georgescu, L. Deleanu, C. Pirvu: Mater SciEng, 147 (2016).

[30] S.D. Heintze, A. Cavalleri, M. Forjanic, G. Zellweger, V. Rousson: Dental Materials, 22 (2006) 1051-1062.

[31] S. Le Roux, C. Boher, L. Penazzi, C. Dessain, B. Tavernier: Tribology international, 52 (2012) 40-49.

[32] M.C. Valigi, S. Logozzo, S. Affatato: Materials, 10 (2017) 548.

[33] R.J.K. Wood, P. Ramkumar, L. Wang, T.J. Wang, K. Nelson, E.S. Yamaguchi, N. Otin: Tribology and Interface Engineering Series, 48 (2005) 109-121. 
[34] P. Heilmann, J. Don, T.C. Sun, D.A. Rigney, W.A. Glaeser: Wear, 91 (1983) 171190.

[35] S.L. Rice, H. Nowotny, S.F. Wayne: Wear, 74 (1981) 131-142.

[36] P.D. Srivyas, M.S. Charoo: Journal of Tribology, (2020) 1-29

$$
\text { (c) (†) Creative Commons License }
$$

This work is licensed under a Creative Commons Attribution 4.0 International License. 